\title{
NUMERICAL ANALYSIS AT THE NATIONAL BUREAU OF STANDARDS*
}

\author{
JOHN TODD
}

\begin{abstract}
In 1946/47, Dr. E. U. Condon (1902-1974), the fourth director of the National Bureau of Standards, arranged for the organization of a Division of Applied Mathematics, under the leadership of Dr. John H. Curtiss. A principal objective of this division was the development of the mathematics appropriate for the automatic digital computing machines then being constructed. An account is given here of some of the activities in numerical analysis carried out by that division in its first 25 years.
\end{abstract}

I am very glad to speak on this subject. Mrs. Todd and I spent about 10 years, 1947-57, at the NBS- she as a resident consultant and I in various capacities. On the whole it was a happy and exciting time, but there were several heartaches. More recently I have been a member of the NASNRC Advisory Panel.

It is difficult to summarize 25 years' work of an organization in the time and space allotted and so I must restrict my coverage severely and apologize for omissions, deliberate or inadvertent. I shall confine myself to more theoretical numerical analysis, omitting discussions of (1) the solutions of special computational problems, which are one of the major contributions of the NBS group, (2) the various tables prepared to aid in statistical analyses [45] and the evaluation of computer programs (e.g., least squares by R. H. Wampler [36], [37]), (3) the more recent work on combinatorial algorithms [38], (4) collaboration in the development of Omnitab [32].

Detailed accounts of the work of the Applied Mathematics Division are given in the various progress reports which are available. Some of the technical material appeared in the Applied Mathematics Series of which over 60 volumes have been published to date and in the Journal of Research of the National Bureau of Standards (since 1947 and especially since 1968 when separate issues were devoted to Mathematical Sciences).

It is almost exactly 25 years since the start of modern numerical mathematics at NBS. Personally, I consider the beginning of modern numerical mathematics took place about 1936. This was the date of Comrie's paper [1] showing how to use business machines for scientific purposes - a thing which we are still doing - and of Turing's first papers [2]; about this time also Ostrowski introduced the "Horner" as a unit for scientific computation [3], and studied the numerical stability of the Newton process [4]. I am, however, far from objecting to the choice of the appearance of the von Neumann-Goldstine paper [5] as the zero date, for it and the companion Turing paper [6] influenced my scientific development insofar as I wrote half a dozen papers on condition numbers [7].

The actual prospectus for the National Applied Mathematics Laboratories was dated February 1947. [This name was abandoned in the early 1950s so I shall speak of the Applied Mathematics Division (AMD).] I actually arrived late

* Received by the editors September 17, 1973. Presented at the SIGNUM-SIAM Panel, October 17, 1972 , on the 25 th anniversary of modern numerical mathematics.

$\dagger$ Department of Mathematics, California Institute of Technology, Pasadena, California 91125. The preparation of this survey was supported in part by the National Science Foundation. 
in September 1947 to join the staff of the Institute for Numerical Analysis (INA), which was one of several sections into which the AMD was divided. Mrs. Todd and I traveled in a troop ship from London with 100 war brides in the officers' cabins; Mrs. Todd was in the sergeants' quarters and I was down in the hold. It was a Liberty ship and, having spent some time earlier on the analysis of the losses of welded ships, I was not always too happy among the creaking bulkheads.

Actually it was only in April 1948 that Prof. O. Szász, Mrs. Todd and I joined Dr. G. Blanch at INA which was located on the campus of the University of California at Los Angeles (UCLA) having spent the time between at the NBS in Washington and in Princeton with von Neumann at the Institute for Advanced Study Computer Project.

The contribution of Professor John H. Curtiss to the development of modern numerical mathematics cannot be overestimated. Like many of us he was first (and still is) a pure mathematician. He got involved in statistics as a Naval officer in World War II and then was a focal point for the development of a central federal mathematical establishment, a project supported by various agencies, notably the Office of Naval Research. The idea for this activity apparently originated in 1965 in the Office of Planning and Invention of the Navy Department. Part of his administrative contributions should be clear from this survey; for his technical contributions we note his work on Monte Carlo [34], his work on the conjugate direction method [33] and a long series of substantial contributions to the theory of approximation from which we cite only two [35].

[On the other side of the Atlantic, I had organized an Admiralty Computing Service (ACS) and later, with my colleagues in it (especially A. Erdélyi and D. H. Sadler), worked toward the foundation of a British National Mathematical Laboratory - this ultimately was incorporated as a division of the British National Physical Laboratory and is the organization with which $\mathbf{J}$. H. Wilkinson has long been associated and of which A. M. Turing was a member. [For some of these activities see [8].]

I digress briefly here to call attention to the fact that one of the first contacts von Neumann had with programming computers occurred during his visit to the ACS in 1943. [For details see [9].]

Dr. Curtiss realized that any experienced pure mathematician could find, if he chose, attractive and challenging problems in numerical mathematics and he recruited established mathematicians as administrators and staff for AMD. Naturally, there were a few recruits who did not respond to the challenges.

In the accompanying diagram I have listed the leaders of groups and given related information indicating the part played by the AMD in the formation of professional societies, the establishment of journals and some of the contributions of its members to the literature.

L. J. Briggs, E. U. Condon, A. V. Astin and L. W. Branscomb were the directors of the NBS in the periods 1933-45, 1945-51, 1951-69, 1969-72, respectively. J. H. Curtiss, E. W. Cannon and B. H. Colvin were the chiefs of the AMD in the periods 1946-53, 1955-71, 1972 respectively.

Let me note that there was already a solid basis for computation at NBS - the Lowan group, whose activities have been described by Lowan [31]. This became a nucleus for the Computation Laboratory $(\mathrm{CL})$, another section of the AMD. 
National Applied Mathematics Laboratories 1947-1954

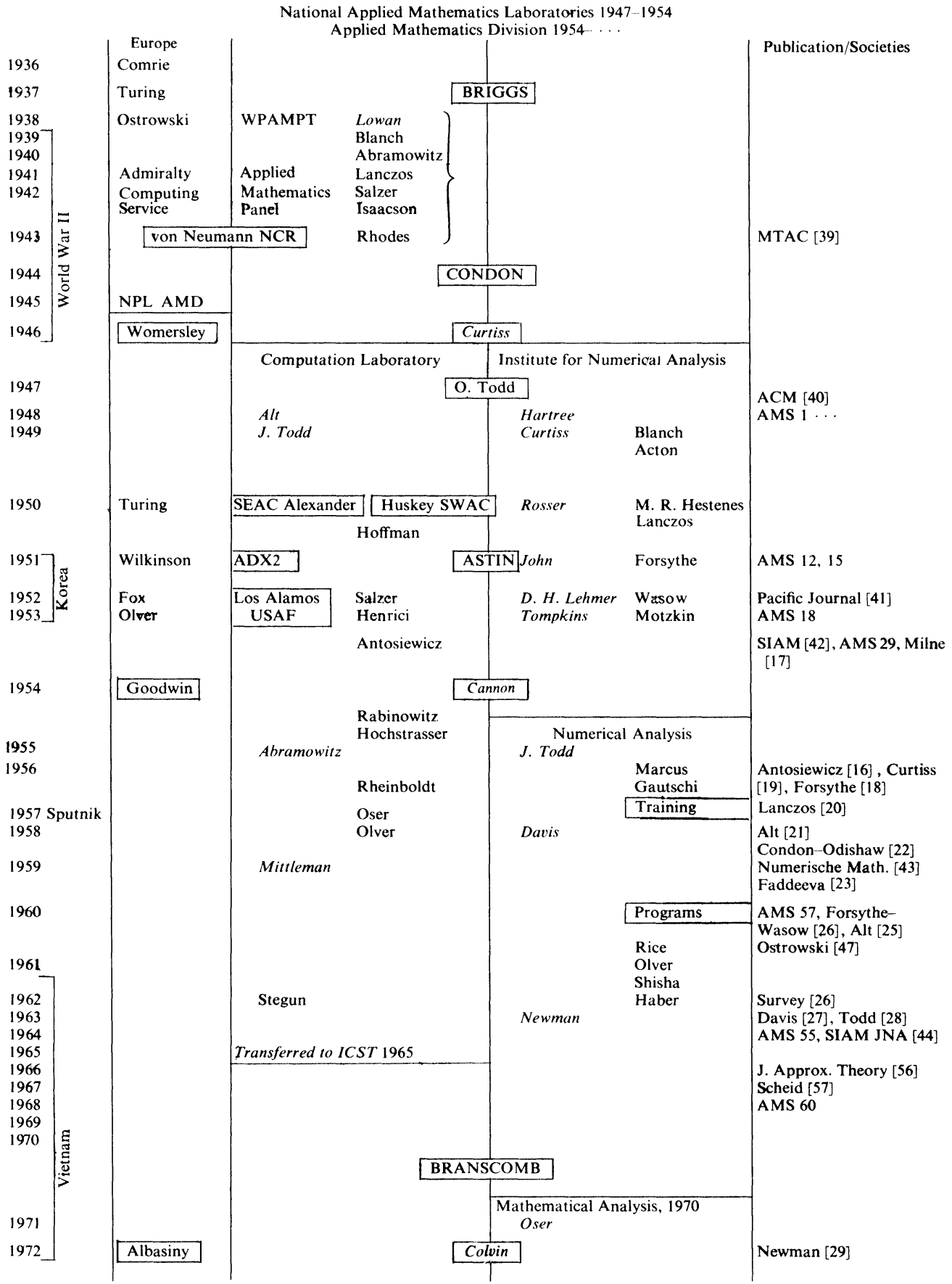


Governments, and other institutions, have their ups and downs. The INA operation at UCLA was unfortunately terminated in 1954; at this time a Numerical Analysis Section (NA) was set up in Washington. The CL was transferred to what is now the Institute for Computer Sciences and Technology in 1965 and the NA was absorbed into a Mathematical Analysis section in 1970. Due to these events and to personnel changes and deaths (e.g., of Abramowitz, Tompkins and Motzkin) the residual operations in numerical mathematics at UCLA and Washington are now a small shadow of what they were in the early 1950s although other areas have flourished and been developed according to the national needs. However the alumni of NBS are now scattered all over the world continuing to develop numerical mathematics and all have a lasting affection for Dr. Curtiss and the NBS and its directors, Dr. Condon and Dr. Astin, who supported their work.

Before discussing in more detail the activities in numerical analysis let me acknowledge the contributions of F. L. Alt and, more recently, of A. J. Goldman in various capacities in the AMD, of $\mathrm{S}$. N. Alexander and H. D. Huskey in providing machines, and for the basic training on them which many had from I. Rhodes.

INA 1947-54. After a short stay by Hartree the first efforts of INA were led by Dr. Curtiss in the directions of Monte Carlo and conformal mapping. Symposia on these topics were organized-see AMS 12, AMS 18 and its sequel, AMS 42. Professor Wasow and Dr. Curtiss were active in Monte Carlo and work in this area is continuing in Washington under Dr. Haber.

Rosser led an effort on matrix problems. This period included the 50th anniversary of the NBS which was marked by "Gatlinburg-1", a symposium largely planned by Mrs. Todd; she, with Paige, edited the Proceedings, AMS 29; sequels to this, AMS 39, 49 appeared later. Highlights of this have been mentioned by Prof. Householder, notably the so-called conjugate direction method. A brief sketch of this method follows. (This is based in part on an account included in $[0(e)]$ due to G. E. Forsythe.)

The solution of an $n \times n$ linear system $A x=b$ is equivalent to the minimization of $f(x)=\|A x-b\|_{2}$, and so, essentially, the determination of the vertex $V$ of an elliptic paraboloid $\pi$. A method of steepest descent consists in moving from a point $P_{0}$ on $\pi$ in the direction of steepest descent at $P_{0}$ to a point $P_{1}$, which is the local minimum. From $P_{1}$ we move similarly in the direction of steepest descent at $P_{1}$. It can be shown that $P_{n} \rightarrow V$. This is, in general, an infinite process. Using the geometrical fact that the midpoint of parallel chords of an ellipse lie on the conjugate diameter, an iterative scheme can be set up which terminates in at most $n$ steps. This scheme was devised in 1951, simultaneously by E. Stiefel in Zürich and M. R. Hestenes at INA. There was considerable preliminary work at INA in which Forsythe, Karush, Motzkin and Rosser also participated. At the same time Lanczos, also at INA, adapted his (1950) method of minimized iterations for the determination of the characteristic polynomial of $A$ to one for the solution of $A x=b$ and arrived at the same conjugate direction method. There was much further work at INA by Paige, M. Stein, Hayes, Hochstrasser, L. Wilson and Curtiss. The definitive report is [30].

It is probably fair to say now that although the conjugate direction method has not been as successful as originally thought for the linear equation problem, 
it has proved very satisfactory in connection with certain optimization problems and for certain sparse systems of equations.

The next period was under the influence of Fritz John when attacks were made on problems of partial differential equations, with contributions by Blanch, Forsythe and Wasow. Milne worked on his book on ordinary differential equations [17]. Representative publications are cited under [53].

Next the Lehmers came to INA and there were some changes in the direction of number theory. Representative publications are cited under [52].

Lehmer was followed by Tompkins whose interests included linear programming, and the calculus of variations. Representative publications are cited under [54].

Throughout this period, M. R. Hestenes and Forsythe [55] were always active and, for part of it, Acton, Lanczos, Motzkin and Karush were involved.

Various training programs took place in the summers.

CL 1947-54. The research activities during this period were largely concerned with mathematical tables under Abramowitz and Stegun, interpolation under H. E. Salzer and with linear programming. The latter subject was created and promoted by G. B. Dantzig: the work at NBS was developed by A. J. Hoffman, in part in collaboration with Motzkin at INA. Hoffman and Antosiewicz [16] ran a symposium on this topic in Washington in 1955.

In addition, Mrs. Todd started a project on the estimation of eigenvalues of matrices and functions of matrices and one in number theory in which both the young postdoctoral staff and the senior visitors participated. Representative publications are cited in [46].

As regards actual computation: this was on a rather small scale due to the "occupation" of SEAC by USAF and the AEC: The USAF actually paid for the machine and the AEC donated a building so that we could be near it. Among the work accomplished was work of a number theoretical character started by Mrs. Todd (Monte Carlo, consecutive power residues $\bmod p$ (with J. C. P. Miller), Wilson primes and the Baker-Campbell-Hausdorff formula (K. Goldberg)) and some controlled experiments on conformal mapping [48], and on linear programming [49].

Towards the end of this period there was the ADX2 incident and a change of administration which led to a heavy reduction in force. There seems to be no connected account of the happenings available-this is an opportunity for a science historian with illustrations available from Herblock. It will be recalled that government scientists were reprimanded for not taking account of "the play of the marketplace" and that the director, Dr. Astin, was asked to resign, but was reinstated, and the NBS decisions were fully supported by a special committee appointed by the National Academy of Science. One outcome of this was an investigation of the NBS as a whole by a select committee under the chairmanship of Dr. M. J. Kelly. In the report of this committee (submitted 15 October 1953) the Applied Mathematics Division was one of two which were specially commended. However this committee deferred to the Applied Mathematics Advisory Council for recommendations on the future of the INA which was then, with the rest of the AMD, in a precarious financial situation due in part to a decision of the Department of Defense not to permit transfer of funds to the NBS. 
1954-70. The numerical analysis activities were concentrated in Washington under my direction and at this time Abramowitz took over the CL. In my time the main emphasis was on controlled computational experiments, e.g., the evaluation of matrix inversion programs with M. Newman [50], who had prepared one of the first matrix packages. This was continued after I left NBS in 1957 by my successor P. Davis, who, for example, with Rabinowitz studied orthonormalization methods [51]. Davis also exploited functional analytic methods (cf. [27]). Davis left in 1963 and his successor, Newman, was largely occupied by number theory, e.g., exact solution of linear systems, until the Numerical Analysis section was merged into a Mathematical Analysis section whose chief is Oser in 1970. However, during this period there was outstanding work by J. R. Rice, a postdoctoral research associate working on approximation theory. I organized a Training Program for Numerical Analysts in 1957-this resulted in the "Survey" [26]. A repetition of this, again with NSF support, was organized by Davis in 1960.

One of the outstanding events of this period was the publication in 1964 of AMS 55 which was prepared by Abramowitz and Stegun and their team. To date about 200,000 copies have been sold and nine printings have been made. (This number includes the sales of a softback Dover edition.)

There were several other significant expository works in this period. The chapters on mathematics in the Condon-Odishaw Handbook of Physics [16] were almost all prepared by members of the AMD. In 1960 A. M. Ostrowski's 1952 lecture notes appeared in book form [47] and AMS 57, Basic theorems in matrix theory, by M. Marcus was published: these have become standard references in many numerical analysis courses. In 1968, AMS 60, Matrix representations of groups, by $\mathrm{M}$. Newman was published.

Finally, let me mention some who participated in the work in Washington or in Los Angeles or both and who contributed to numerical mathematics:

S. Agmon, L. Bers, H. Cohn, Ky Fan, J. M. Hammersley, T. Kato, J. C. P. Miller, A. M. Ostrowski, I. J. Schoenberg, P. Stein, E. Stiefel, H. Wielandt. (I omit those summer visitors at Los Angeles who were involved in a classified project.)

Among the "younger" people who "graduated" from the NBS during this period were F. S. Acton, E. C. Dade, H. P. Edmundson, Walter Gautschi, A. A. Goldstein, R. M. Hayes, P. Henrici, U. W. Hochstrasser, M. Muller, W. C. Rheinboldt, J. R. Rice, F. Scheid, J. L. Selfridge, T. H. Southard (a former SIAM President), M. L. Stein, D. Teichroew and C. Witzgall.

To conclude, let me enumerate some probable firsts in numerical mathematics which were carried out at the NBS during the first 25 years of the AMD:

(a) Automatically computed earth-moon trajectory [10]. (Earlier, rocket/ comet orbits were tabulated by Herrick using punched card equipment : See AMS 20 (1953).)

(b) Optimal scaling of matrices [11].

(c) Computational complexity [12], [13].

(d) Studies of the Hilbert matrix [14], [15], [46(a)]. 


\section{REFERENCES}

0] (a) Activities in Applied Mathematics 1946-1967.

(b) Projects and Publications of the Applied Mathematics Division: quarterly 1947-1962,

(c) J. H. CurTiss, A federal program in applied mathematics, Science, 107 (1948), pp. 257-262. semiannually $1963-$.

(d) —_. Some recent trends in applied mathematics, American Scientist, 37 (1969), (\#4), pp. $587 \mathrm{ff}$.

(e) - The NAML of the NBS. A progress report covering the first five years of its existence, April 1, 1953, unpublished.

(f) Applied Mathematics Series 1 (1948). To date over 60 volumes have been published by the U.S. Government Printing Office. We refer specifically to the following:

AMS 12 (1951), Monte Carlo method, Proc. of a Symposium, June 29, 30, July 1, 1949, A. S. Householder, ed.

AMS 15 (1951), Problems for the numerical analysis of the future, Four papers presented at Symposia, July 25-31, 1948. Foreword by J. H. Curtiss.

AMS 18 (1952), Construction and applications of conformal maps, Proc. of a Symposium, June 22-25, 1949, E. F. Beckenbach, ed.

AMS 42 (1955), Experiments in the computation of conformal maps, John Todd, ed.

AMS 29 (1953), Simultaneous linear equations and the determination of eigenvalues, Proc. of a Symposium, Aug. 23-25, 1951, L. J. Paige and Olga Taussky, eds.

AMS 39 (1954), Contributions to the solution of systems of linear equations and the determination of eigenvalues, Olga Taussky, ed.

AMS 49 (1958), Further contributions to the solution of systems of equations and the determination of eigenvalues.

AMS 57 (1960), Basic theorems in matrix theory, M. Marcus.

AMS 65 (1964, 9th printing 1972), Handbook of Mathematical Functions with Formulas, Graphs and Mathematical Tables, M. Abramowitz and I. A. Stegun, eds.

[1] L. J. Comrie, Inverse interpolation and scientific applications of the National Accounting Machine,

J. Roy. Statist. Soc. Supplement, 3 (1936), pp. 87-114.

[2] A. M. TURING, On computable numbers with an application to the Entscheidungsproblem, Proc. London Math. Soc., $\{2\} 42$ (1936/7), pp. 230-265.

[3] A. M. Ostrowski, On Newton's method of approximation. British Assoc. Adv. Science Reports, 1938, p. 392.

[4] __ Über die Konvergenz und die Abründungsfestigkeit des Newtonschen Verfahren. Rec. Math., 2 (1937), pp. 1073-1098.

[5] J. von Neumann ANd H. H. Goldstine, Numerical inverting of matrices of high order, Bull. Amer. Math. Soc., 53 (1947), pp. 1021-1097; Proc. Amer. Math. Soc., 2 (1951), pp. 188-202.

[6] A. M. TURING, Rounding-off errors in matrix processes, Quart. J. Mech. Appl. Math., 1 (1948), pp. 287-308.

[7] JoHN TODD, On condition numbers, Programmation en mathématiques numériques $\equiv$ Coll. Intern. du CNRS, \# 165, 1968, pp. 141-159.

[8] (a) D. H. SADler AND John TOdD, Admiralty computing service, MTAC, 2 (1947), pp. 289-297.

(b) - Mathematics in government service and industry. Some deductions from the war-time experience of the Admiralty Computing Service, Nature, 157 (1946, 4 May), pp. 571-573.

(c) A. ERDÉlyi AND JoHN TODD, Advanced instruction in practical mathematics, Ibid., 158 (1946, 16 November), pp. 690-692.

[9] JoHn ToDD, John von Neumann and the National Accounting Machine, SIAM Rev., 16 (1974), pp. 526-530.

[10] C. E. FröBerg AND A. A. Goldstein, A collision path from the earth to the moon in the restricted problem of three bodies. Kungl. Fysiografiska Sällskapets i Lund Förhandlingar, 22 (1952), no. 14,3 pp.

[11] G. E. Forsythe and E. G. Straus, On best conditioned matrices, Proc. Amer. Math. Soc., 6 (1955), pp. 340-345.

[12] A. M. Ostrowski, On two problems in abstract algebra connected with Horner's rule, Studies presented to R. von Mises, Academic Press, New York, 1954, pp. 40-68.

[13] T. S. Motzkin, Evaluation of rational functions: Evaluation of polynomials, Abstracts 314, 315, Bull. Amer. Math. Soc., 61 (1955), p. 163. 
[14] T. Kato, On positive eigenvectors of positive infinite matrices, Comm. Pure Appl. Math., 11 (1958) . pp. 573-586. (For references to further work on this topic see [15].)

[15] JoHn ToDD, Computational problems concerning the Hilbert matrix. J. Res. Nat. Bur. Standards Sect. B, 65 (1961), pp. 19-22.

[16] H. A. Antosiewicz, ed., Second Symposium, Linear Programming. 2 vols., National Bureau of Standards, Washington, D.C., 1956.

[17] W. E. Milne, Numerical Solution of Differential Equations, John Wiley, New York, 1953.

[18] G. E. Forsythe, Bibliography of Russian Mathematics Books, Chelsea, New York, 1956.

[19] J. H. Curtiss, ed., Numerical Analysis, Proc. Symposia in Applied Mathematics, vol. 6, McGrawHill, New York, 1956.

[20] C. Lanczos, Applied Analysis, Prentice-Hall, Englewood Cliffs, N.J., 1956.

[21] F. L. Alt, Electronic Digital Computers, Academic Press, New York, 1958.

[22] E. U. Condon And H. Odishaw, Handbook of Physics, McGraw-Hill, New York, 1st ed., 1958, 2nd ed., 1967.

[23] V. N. Faddeeva, Computational Methods of Linear Algebra, Dover, New York, 1959.

[24] G. E. FORSYTHE AND W. R. WASOW, Finite difference methods for partial differential equations, John Wiley, New York, 1960. (Russian transl. 1968, Japanese transl. 1968.)

[25] F. L. Alt, ed., Advances in Computers, vol. 1, 1960, Academic Press, New York

[26] JoHn Todd, ed., Survey of Numerical Analysis, McGraw-Hill, New York, 1962.

[27] P. J. DAvis, Interpolation and Approximation, Blaisdell, New York, 1963.

[28] JoHn ToDD, Introduction to the Constructive Theory of Functions, Academic Press, New York, 1963.

[29] M. Newman, Integral Matrices, Academic Press, New York, 1972.

[30] (a) M. R. Hestenes AND E. STIEFEL, Method of conjugate gradients for solving linear systems, J. Res. Nat. Bur. Standards, 49 (1952), pp. 409-436.

(b) M. R. HESTENES, The conjugate-gradient method for solving linear equations, pp. 83-102 in [19].

[31] A. N. Lowan, The Computation Laboratory of the National Bureau of Standards, Scripta Math., 15 (1949), pp. 33-63.

[32] ОмniтAв, A computer program for statistical and numerical analysis, J. Hilsenrath, G. G. Ziegler, C. G. Messina, P. J. Walsh, R. J. Herbold, NBS Handbook 101 (1966-reissued 1968). Various related material has been issued as NBS Tech. Notes 446, 550, 551, 552 and NBS Special Publication 339.

[33] J. H. CuRTiss, A generalization of the method of conjugate gradients for solving systems of linear algebraic equations, MTAC, 8 (1954), pp. 189-193.

[34] - Sampling methods applied to differential and difference equations, with special reference to equations of elliptic type, IBM Seminar on Scientific Computation, IBM Corp., New York, pp. 87-109.

[35] (a) - Faber polynomials and the Faber series, Amer. Math. Monthly, 78 (1971), pp. 577 596.

(b) - Overdetermined harmonic polynomial interpolation, J. Approx. Theory, 5 (1972), pp. 149-175.

[36] R. H. WAMPLER, An evaluation of linear least squares computer programs, J. Res. Nat. Bur. Standards Sect. B, 73 (1969), pp. 59-90.

[37] - A report on accuracy of some widely used least squares computer programs, J. Amer. Statist. Assoc., 65 (1970), pp. 549-565.

[38] (a) J. EDmonds, Minimum partition of a matroid into independent subsets, J. Res. Nat. Bur. Standards Sect. B, 69 (1965), pp. 67-72.

(b) - Lehman's switching game and a theorem of Tutte and Nash-Williams, Ibid., 69 (1965), pp. 73-77.

(c) - Maximum matching and a polyhedron with 0,1-vertices, Ibid., 69 (1965), pp. 125-130.

(d) J. Edmonds AND D. R. Fulkerson, Transversals and matroid partition, Ibid., 69 (1965), pp. 147-153.

(e) J. Edmonds, Optimum branchings, Ibid., 71 (1967), pp. 233-240.

(f) - Systems of distinct representatives and linear algebra, Ibid., 71 (1967), pp. 241-245. 
[39] MTAC (Mathematical Tables and Other Aids to Computation) was founded by the National Research Council in 1943 under the editorship of R. C. Archibald and D. H. Lehmer, with the cooperation of L. J. Comrie and S. A. Joffe. The title was changed to Mathematics of Computation in 1960 with the appearance of volume 14. We note that publication was taken over by the American Mathematical Society in 1963 and that a Cumulative Index to Mathematics of Computation; 1-23, 1947-1969 was published in 1972. The NBS AMD has taken a considerable part in the editorial work for this journal. Among the later editors were E. W. Cannon, J. Todd, C. B. Tompkins, E. Isaacson, P. J. Davis, A. J. Hoffman, W. Gautschi, P. Rabinowitz.

[40] The Association for Computing Machinery was founded in 1947. The first president was J. H. Curtiss, the third was F. L. Alt (who was given the distinguished Science Award in 1970). Later H. D. Huskey and G. E. Forsythe were presidents of ACM. M. R. Kellington has been editor of ACM since 1959, having served the AMD in a similar capacity since 1948. For further information about ACM see, e.g., Comm. ACM, 15 (1972), no. 7.

[41] Although the Pacific Journal of Mathematics received much support from the NBS in its early days (see e.g., [0(e)]) it never developed into a major one in numerical mathematics.

[42] The Society for Industrial and Applied Mathematics was founded in 1953. One of its early presidents was T. H. Southard, the current president is B. H. Colvin.

[43] Numerische Mathematik was founded in 1959 and former members of the NBS AMD have been active editorially. E. Stiefel and John Todd have been editors-in-chief since the beginning and G. E. Forsythe, W. Gautschi and P. Henrici have been or are associate editors.

[44] The SIAM Journal of Numerical Analysis was founded in 1964. Among those who have served as editors are P. Henrici, F. W. J. Olver and W. C. Rheinboldt.

[45] The following AMS volumes are relevant: 6, 7, 21, 22, 23, 24, 33, 41, 44, 47, 48, 50, 54, 58, $62,63$.

[46] (a) O. TAUSSKY, A remark concerning the characteristic roots of the finite segments of the Hilbert matrix, Quart. J. (Oxford), 20 (1949), pp. 80-83.

(b) - A recurring theorem on determinants, Amer. Math. Monthly, 56 (1949), pp. 672-676.

(c) - Note on the condition of matrices, MTAC, 4 (1950), pp. 111-112.

(d) T. S. Motzkin And O. TAussky, Matrices with property L, Trans. Amer. Math. Soc., 73 (1952), pp. 108-114

(e) P. Stein, Some general theorems on iterants, J. Res. Nat. Bur. Standards, 48 (1952), pp. 83-83.

(f) A. J. Hoffman AND H. W. Wieland, The variation of the spectrum of a normal matrix, Duke Math. J., 20 (1953), pp. 37-39.

(g) Ky FAN AND A. J. Hoffman, Lower bounds for the rank and location of the eigenvalues of a matrix, AMS 39, pp. 117-135.

(h) A. J. Hoffman And O. TAussky, A characterization of normal matrices, J. Res. Nat. Bur. Standards, 52 (1956), pp. 17-19.

(i) Ky FAN, O. TAUSSKY AND J. TODD, Discrete analogs of the inequalities of Wirtinger, Monatsh. Math., 59 (1955), pp. 73-90.

(j) H. Wielandt, An extremum property of sums of eigenvalues, Proc. Amer. Math. Soc., 6 (1955), pp. 106-110.

(k) - Error bounds for eigenvalues of symmetric integral equations, pp. 261-282 in [19].

(l) O. TAUSSKY, Some computational problems in algebraic number theory, pp. 187-193 in [19].

(m) - Commutativity in finite matrices, Amer. Math. Monthly, 65 (1952), pp. 223-235.

(n) Ky FAN, Note on circular disks containing the eigenvalues of a matrix, Duke Math. J., 25 (1958), pp. 441-445.

(o) O. TAussKy, Matrices of rational integers, Bull. Amer. Math. Soc., 66 (1960), pp. 327-348.

(p) - Some computational problems involving integral matrices, J. Res. Nat. Bur. Standards, 65 (1961), pp. 15-17.

[47] A. M. Ostrowski, Solutions of Equations and Systems of Equations, Academic Press, New York, 1 st ed., 1960, 2nd ed., 1966, 3rd ed., 1973.

[48] (a) S. E. WARSCHAWSKI, On the solution of the Lichtenstein-Gershgorin integral equation in conformal mapping. I: Theory, AMS 42 (1955), pp. 7-29.

(b) JoHn TODD AND S. E. WARSCHAWSKI, On the solution of the Lichtenstein-Gershgorin integral equation in conformal mapping. II: Computational experiments, AMS 42 (1955), pp. 31-44. 
[49] A. J. Hoffman, M. Mannos, D. Sokolowsky and N. Wiegmann, Computational experience in solving linear programs, J. Soc. Indust. Appl. Math., 1 (1953), pp. 17-33.

[50] M. Newman AND J. TodD, The evaluation of matrix inversion programs, Ibid., 6 (1958), pp. $466-476$.

[51] P. J. Davis and R. Rabinowitz, Advances in orthonormalizing computations, pp. 55-133 in [25, vol. 2, 1961].

[52] (a) D. H. LeHMER, On the roots of the Riemann zeta-function, Acta Math., 95 (1956), pp. 251-258.

(b) - Extended computation of the Riemann zeta-function, Mathematika, 3 (1956), pp. 102-108.

(c) E. T. LEHMER, Number theory on the $S W A C$, pp. 103-109 in [19].

[53] (a) F. JoHN, On integration of parabolic equations by difference methods. I, Comm. Pure Appl. Math., 5 (1952), pp. 155-211.

(b) G. Blanch, On the numerical solution of parabolic partial differential equations, J. Res. Nat. Bur. Standards, 50 (1953), pp. 343-356.

(c) W. Wasow, Discrete approximations to elliptic differential equations, Z. Angew. Math. Phys., $6(1955)$, pp. $81-97$.

[54] (a) C. B. ToMPKINS AND D. A. Pope, Maximizing functions of rotations, J. Assoc. Comput. Mach., 4 (1957), pp. 459-466.

(b) C. B. TompKINS, Machine attacks on problems whose variables are permutations, pp. 195-211 in [19].

See also the Obituary Notice, Charles Brown Tompkins in Math. Comp., 52 (1971), pp. 931-933.

(c) T. S. Motzkin, The assignment problem, pp. 109-125 in [19].

[55] For an account of Forsythe's contributions to numerical analysis during this period and later see D. E. Knuth, George Forsythe and the development of computer science, Comm. ACM, 15 (1972), pp. 721-726.

[56] The Journal of Approximation Theory was established by O. Shisha in 1968. Among the associate editors were P. J. Davis, J. R. Rice and John Todd.

[57] F. SCHEID, Numerical Analysis, Schaum's Outline Series, McGraw-Hill, New York, 1968.

Notes added in proof, November 1974.

1. The present [1973- ] director of the NBS is R. W. Roberts.

2. For information supplementary to [31] see

[58] G. Blanch and I. Rhodes, Table-making at the National Bureau of Standards in Studies in numerical analysis. Papers presented to Cornelius Lanczos, B. K. P. Scaife, ed., Academic Press, New York, 1974.

3. Another paper presented at the October 17, 1972 Panel is

[59] A. S. Householder, The Gatlinburgs, this Review, 16 (1974), pp. 340-343. 